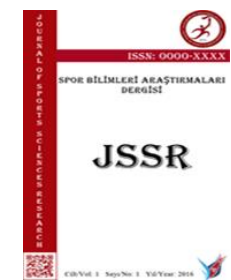

SPOR BİLIMLERİ ARAŞTIRMALARI DERGISİ

Journal of Sport Sciences Researches

http://dergipark.gov.tr/jssr

ISSN: 2548-0723

\title{
An Equity Centered Management Approach to Exploiting Sport Employee Productivity $^{*}$
}

\author{
Robert C. SCHNEIDER ${ }^{1 * *}$ \\ ${ }^{1}$ The College at Brockport, State University of New York, Sport Management Program Director, USA
}

\begin{abstract}
A primary goal of sport organizations is to exploit employees' abilities to their fullest capacities. Sport managers who successfully maximize employee productivity will greatly increase the chances of achieving the organization's goals and objectives. The full potential of sport employees' abilities can be realized through the application of the equity component grounded in Adam's Equity Theory (Adams, 1963). Centered on the premise that the relationship between sport manager and employer must be one of equity, the equity component focuses on achieving equity between what the employee puts into the job, referred to as "employee inputs," and what the employee gets out of the job from the employer, referred to as "sport manager outputs." The input-output equity balance is centered on the moral value of fairness. When fairness is achieved, reasonable employees and employers should be mutually satisfied (Mill, 1863/1957). A shared interest between employees in achieving the goals and objectives of the mission of the sport organization is required if an equitable input-output balance is to be achieved. Lower resistance to realizing a proper balance between inputs and outputs should be expected when an employee's professional interests are naturally aligned with the mission of the sport organization (Kim, 2012). Screening employees during the hiring process to ensure for a congruent employer-employee "fit" is preferable to help ensure for the satisfactory balance of inputs and outputs over the long term. Regardless of the compatibility between the employee's interest and the mission of the sport organization, the often dynamic nature of sport organizations calls for constant maintenance of input-output exchanges. When seeking to balance the inputoutput exchange, sport managers will be well served to heed the insight by Jiang and Men (2017) who stated that productivity follows employee engagement, which comes from transparent communication by organizational leaders. The sport manager who hires employees whose interests align with the sport organization mission will be well positioned to achieve an equitable balance between employee inputs and employer outputs. Doing so is supportive of a sport organization that maximizes its potential for employee productivity.

DOI: $10.25307 /$ jssr.364020

Review

$\underline{\text { Article Info }}$

Received: 08.12.2017

Accepted: 23.12.2017

Online Published: 29.12.2017

Keywords: leadership, governance, human resources, motivation, hiring
\end{abstract}

\footnotetext{
* This study was presented as a keynote speaker in "World Congress of Sport Sciences Researches" congress held in Manisa/TURKEY, between 23-26 November, 2017

** Correspondance Author: Robert C. Schneider

E-mail: rschneid@brockport.edu
} 


\section{INTRODUCTION}

A central goal of sport organizations is to exploit employees' abilities to their fullest capacities. Sport managers who are successful in their attempts to do so will greatly increase their chances of achieving the sport organization's goals and objectives. A formal approach to maximize employee productivity is recommended as the sport manager endeavors to achieve mission based goals and objectives of the sport organization.

Khalifa and Truong (2010) discussed the importance of employee job satisfaction as a predictor of critical work outcomes. It is necessary that that the input-output balance is equitable for employee satisfaction to be realized and to enhance the chances of sport organization productivity.

The full potential of sport employees' abilities can be realized through the application of Adam's Equity Theory (Adams, 1963). Centered on the premise that the relationship between management and employees must be one of equity, Adams Equity Theory places its focus on achieving equity between employee inputs and employer outputs. In the case of sport organizations, the employee is considered the sport manager.

The aim of this article was to apply Adam's Equity Theory to a sport setting for the purpose of providing sport organization based practitioners, i.e., sport managers, with recommendations helpful in improving the collective productivity of their employees. Methodologically, published articles were reviewed that addressed areas related to Adam's Equity Theory, with a primary focus on employer input-employee output exchanges. Discussion of the aforementioned literature concluded with recommendations helpful to sport managers as they aspire to increase the productivity of their employees.

\section{Employee Inputs and Sport Manager Outputs}

Employee inputs can be described as the perceived efforts of the employees and must be met with sport manager outputs. Adams (1963) described the relationship between inputs and outputs as one that should be equal if the condition of employee satisfaction is to be met. The inputs by the employee can come in numerous forms and can vary across sport organizations. Outputs from the sport manager to the employee can also vary across sport organizations. Balancing the employee inputs with sport manager outputs is the goal of the sport manager and is somewhat dependent on the perceived values placed on inputs and outputs of both parties. If Adams Equity Theory is to bring about a productive sport organization, the overall outputs provided by sport managers must be equitable to the employee inputs across the collective assembly of employees.

\section{Employee Inputs}

Employee inputs can come in several forms and must support the mission of the sport organization. The employee's inputs should be identified and met by the sport manager with equitable outputs. A sample list of employee inputs invested by the employee into the sport organization include time, effort, ability, loyalty, tolerance, flexibility, integrity, commitment, reliability, and heart and soul.

Although it is not a purpose of this paper to provide details related to specific employee inputs, it is important that sport managers gain an understanding of the importance of how to reinforce employee inputs that support the mission of the sport organization. The sport 
manager must feel that the employee is providing necessary efforts to adequately support the mission of the organization; whereas, the employee must feel satisfied with the outputs received from the sport manager in return for those inputs.

\section{Sport Manager Outputs}

Employees receive outputs from the sport manager in return for inputs provided to the organization from the employee. If the sport manager outputs in their many forms are to be effective there must be a perceived equity across all parties, including not only the employee and sport manager but also the perception of equity by all employees who form opinions related to the exchange of inputs and outputs of any one particular employee with the sport manager.

\section{Differing Perceptions of Inputs and Outputs}

Differing perceptions of inputs, outputs, and equity is a challenge in achieving equity between inputs and outputs. The employee input and sport manager output exchange must be perceived to be equitable by all workplace parties if satisfaction across the workplace is to be present. Among the many potential challenges to both parties (sport manager and employee) is the perception of what in fact is equitable. Similar to the age old phrase, "beauty is in the eye of the beholder," what one considers equitable can differ not only between the employee and the sport manager but also across different employees and administrators. If the sport manager can meet the challenge of reaching what all workplace parties agree to be equitable in the numerous areas of employee inputs and sport manager outputs, sport organization productivity will be supported.

Given the improbability of universal agreement on equity perceptions across the workplace, an approach that focuses on eliminating inequities as opposed to seeking perfectly agreeable equities is recommended. Similar to utilitarian moral theory where satisfying the most amount of people (Mill 1863; 1957) is considered moral, if the balance between perceived inputs and outputs is satisfactory across the most amount of participants, that balance will be considered to be equitable.

\section{Minimizing Equity Perceptions of Inputs and Outputs by Hiring “Good Fits”}

Understanding perceived equities during the early stages of the professional relationship between the employee and the sport manager, i.e., the hiring process, is helpful when the input-output equity process takes place across personnel throughout the organization. Hiring employees who are naturally good "fits" to the mission of the organization supports organizational goal achievement (Childs, 2009). Screening employees during the hiring process can help minimize differing perceptions of input and outputs. If employees and the sport manager hold similar perceptions of inputs and outputs, the equity process will be more easily met than if perceptions differ. Narrowing the gap between differing perceptions of inputs and outputs between employees and sport managers will allow equity to take place more easily than if the perceptions differ widely. The focus on mitigating differing perceptions of inputs and outputs should take place in the early stages of the hiring process. Reviewing resumes, questioning references, and interviewing prospective employees are all strongly recommended as means to determine sport manager and employee perceptions of equity as it exists at the workplace. Clarifying sport managers' expectations in the job description is helpful in attracting employees whose views of equity are the same or similar to the sport manager's perceptions of equity. 


\section{Consistently Measuring the Input-Output Balance}

Consistently gaging the perceptions of equity between employees and sport manager is necessary to ensure the best chance for mutual satisfaction between employees and sport manager. Understanding each party's interpretation of what constitutes equity on a biannual basis or more frequently can be helpful in preventing widening perceptions between employee and sport manager as to what constitutes equity when attempting to balance inputs with outputs.

Identifying differences can provide each party with the opportunity to regain a mutual understanding of equity within an ever-changing work environment. In a best-case-scenario, employee and sport manager will agree on what each perceive to be equitable and carry on with the business of the sport organization. Equally preferable by both parties, would be that the employee terminate employment with the sport organization, in the event that the employee and sport manager's perceptions of equity between inputs and outputs differ widely. It is best if employees identify organizations where they are in general agreement with their sport manager's views in regards to what constitutes equity in the input-output exchange. A worst-case-scenario sees the employee and sport manager at extreme odds as to what constitutes equity, yet they remain together in the organization. Usually the result is conflict, coming at the expense of organizational productivity.

\section{Formal and Informal Assessments}

The more common organizational relationship between the employee and sport manager is one that includes employees who are good fits with the mission and purposes of the sport organization. Consistent equity assessments are required to maintain and incentivize the highest possible levels of employee effort. Proper maintenance of appropriate input-output equity balances must be an ongoing process between employee and sport manager. Often informal insights of equitable inputs and outputs can be incorporated into more formal assessments. Ongoing equity assessments are necessary to maintain such a balance, supporting the highest possible productivity across employees in the sport organization.

No matter how perfect the fit, as a sport organization evolves, ongoing assessment of employee-sport manager equity perceptions is required because the likelihood of a perfect fit remaining perfect over time low. Constant equity assessments are required to maintain good fits, let alone perfect fits.

\section{Identifying Sport Manager Outputs}

Sport manager outputs can be unique to particular places of employment and as mentioned previously can be many. A sport manager output must be of value to an employee. Given the broad interests of what employees' value, the range of sport manager outputs can be vast. It is recommended that organizations seek to identify areas or items of value that are unique to their organization, which can serve as outputs. Conducting employee surveys can also be helpful to determine effective sport manager outputs. It must be emphasized that outputs will only be effective if they are valued by employees. Regardless of the array of possible outputs, some are common across organizations and are discussed in detail in the following section.

\section{Pay}

Pay, sometimes referred to as salary or wages, might be the most effective of all of the outputs. Employees often assess equity first and foremost based on the amount of their salary as it relates to perceived employee inputs. Employees' commitment to top-management goals, effort, and cooperation determined by their pay equity perceptions can affect both the quantity and quality of organizational products (Cowherd \& Levine, 1992). 
Wages in line with the market were found to diminish employee fluctuation (Burtaverde \& Mihaila, 2013). Early in the negotiation process, salary should be discussed in accordance with the job expectations of the employees. Throughout the term of employment, salary should be revisited by the sport manager and adjusted based on recent past inputs and anticipated future inputs. Many are the cases where employees perceive their salary to be incommensurate with inputs to the sport organization. Even though several additional outputs are readily available to the sport manager, base salary continues to be a most influential output during the employee and sport manager joint attempts to achieve equity. Salary and its effective distribution can strongly influence the satisfaction of employees (Hay, 1948).

\section{Bonus and Perquisites}

Beyond salary, employee bonuses and perquisites (perks) are also effective outputs that can be monetarily based. Sport managers can present bonuses to an employee on a one-time basis or as often as deemed appropriate. Bonuses frequently are given to employees in the form of monetary payouts but are not added to the base salary and thus, are not as valued as base salary pay raises.

Perks, can also take place in the form of money but more often are non-financial incentives. Sometimes referred to as fringe benefits, perks have been found to strongly influence organizational performance (Aslam \& Mundayat, 2016). Perks are often cost free for the sport manager and may include a wide range of incentives such as continuing education, flexible work hours, concierge services, access to mental and physical health centers, dining services, housing, and work-place commute and parking services. Oftentimes unique to a particular work-place domain and culture, perks serve as effective outputs for sport managers, as they enhance employee satisfaction.

Sport managers are well served to invest the necessary time to identify and create perks that support the needs and wants of employees. As with most outputs, some perks are deemed more desirable than others, depending on individual employee interests. Reinforcing the popularity of perks is their cost effectiveness. Often, from an employer standpoint, perks are cost effective, which reinforces their popularity.

Large sport organizations can often enter into agreements with agencies who can offer bulk services at affordable prices, making this output a financially attractive one from both an employee and sport manager standpoint. In place of direct monetary offerings, the sport manager can pay an agency a reduced rate for a selected service, e.g., insurances, lodging fees, rental car rates, which in turn is offered to employees in place of the amount of money it would require an individual employee to receive said service. This type of arrangement is advantageous to both the sport manager and employee as they endeavor to reach a point of mutual satisfaction relative to the sport manager-employee equity balance.

\section{Benefits}

Benefits support the general well-being of the employee and can come in a broad array of forms, which are relevant to the equity assessment of employees. Considered to be benefits are any compensation beyond wages or salary, such as health, dental, life, disability, vacation and time off, retirement, daycare, sick leave, in addition to other aspects of overall working conditions (Spell \& Bezrukova, 2012). The magnitude of a selected benefits is based on the value each individual employee places on it. Some employees might prefer an extra week of vacation in place of a guaranteed increase to their base salary. Thus, the desire for particular benefits differs across employees, depending on the employee's needs and wants. One 
employee might consider family health benefits a stronger output than an increase to base salary pay; whereas, another employee might prefer the increase to base salary pay.

\section{Security}

Security, as a workplace output, can help satisfy employees. Whereas some employees care exclusively about compensation in the form of spendable currency, others might prefer a higher degree of job security over money. The security of knowing that one will be employed over a period of several years is sometimes more preferable than receiving and exorbitant salary without the guarantee of being employed for the long-term.

\section{Recognition and Praise}

Some outputs such as recognition, and praise do not require extensive time and effort on the part of the sport manager but can be highly effective in reinforcing appropriate organizational employee behaviors that support the organizational mission. Recognition of employees, supports their satisfaction and helps organizations attain objectives (Alonzo, 2007). Praise, when delivered regularly to employees, supports their perception of equity when weighing the input-output balance. If, however, praise is verbalized for the sole purpose of shaping behavior it is debatable as to whether it is considered an output. Praise can only be considered an output if the recipient considers it worthy in the sense that it contributes to establishing equity when weighing the employee's inputs against the outputs received. As with all of the sport manager outputs the weight of recognition and praise is only as worthy as the value placed on them by the employee.

\section{Responsibility}

A true "win-win" for the sport manager-employee equity relationship can come in the form of sport manager outputs that are valued by the employee and that increase the productivity of an organization. Assigning additional wanted responsibilities to the employee workload is such an output. Many motivated employees embrace more responsibility as they aspire to continually improve their work abilities and seek to advance professionally. Responsibility can only be given to employees who possess the requisite skills to assume and perform the new roles and duties successfully. If employees across the work place become more satisfied as a result of being assigned more responsibility, the sport organization will experience a rise in productivity.

\section{Enjoyable Work Environment}

Creating an enjoyable workplace environment can serve as a highly valued sport manager output. Sport organizations should invest time and resources into establishing a work environment that employees enjoy. A workplace culture consisting of persons whose character is upstanding will equate to an overall collegial workplace where employees share mutual respect for one another. Far too often, workplaces are less than enjoyable because of the prevailing negative attitudes of just a few. Sport managers will be well served to hire employees whose character will be positively received by colleagues in a way that generates feelings of enjoyment.

An enjoyable work environment is not to be understood as one that is without pressures to perform. Overly pressurized work environments, however, can result in employee separation from the organization (Burtaverde \& Mihaila, 2013). The sport manager should be aware of the value employees place on an enjoyable work environment as an output in exchange for their inputs. Productivity cannot be compromised in the interest of enjoyment. Enjoyment in the workplace is grounded in ensuring that employees feel a sense of safety and security, 
which allows employees to focus on organizational outcomes instead of lower level motivational needs. Enjoyment is largely a byproduct of working with morally sound coworkers and management who share a collective trust among one another.

\section{Employee Professional Development}

Employee professional development opportunities can also serve as effective outputs for sport managers when seeking to balance the input-output scale with respect to employees and sport managers. Employees who are achievement oriented will value outputs that come in the form of opportunities for professional development. Sport managers can offer professional development in a variety of forms. It can be offered free or discounted and may take place within the organization or outside of the sport organization. If within the organization, professional development endeavors may be conducted by employees or administrators of the organization. Alternatively, professionals may be hired to deliver professional development seminars at the employees' workplace. Another option is to provide support for professional development that takes place outside of the organization, e.g., classes, seminars, and conferences. Full-time coursework, certificate programs, and academic degrees are additional examples of professional development that weigh heavier on the input-output equity scale than one-time seminar type of opportunities.

\section{Outputs Unique to Selected Organizations}

Each sport organization should conduct an output analysis to determine existing outputs or the potential to create outputs unique to their sport organization. Surveying the organization's employees and asking them to weigh their value of selected outputs can be helpful when determining the weight placed on such outputs. Informal open ended inquires can also be helpful in revealing outputs preferred by the employee but unknown to the sport manager. Sport managers may not be aware of differing perceptions of values that employees place on selected employee inputs and also sport manager outputs. A survey that seeks to determine the degree to which employees value employee inputs and sport manager outputs can assist the sport manager in balancing the input-output exchange.

\section{Balancing the Input-Output Exchange}

The process of achieving equity between employee inputs and sport manager outputs is ongoing between the sport manager and employee. When both employee and sport manager reach a state of satisfaction in regards to the input-output exchange, equity is likely. The sport manager must be satisfied that the outputs given to the employee reciprocate equitably with the employee's inputs. In turn, the employee must be satisfied with the outputs received from the sport manager. Both parties must feel a sense of equity and fairness in terms of what they are receiving from the other. The purpose of the on-going communication between sport manager and employee, relative to the equity standing of inputs and outputs is to maintain an adequate level of equity satisfaction. When the employee and sport manager reach a state of satisfaction in terms of equity of inputs and outputs, the work environment becomes enjoyable and conducive to achieving high levels of productivity.

\section{Inequitably Balanced Inputs and Outputs}

Although the goal is to achieve and maintain a mutually satisfactory balance of employee inputs with sport manager outputs, the sport manager must also be aware of inequitable balances in favor of the employee and also in favor of the sport manager. In the event that equity between inputs and outputs is not achieved, employee behaviors not conducive to the sport organization's productivity may begin to surface and should be anticipated. The examples of negative employee behaviors resulting from unbalanced input-output exchanges 
not favoring the employee are many. Workplace theft was one such negative behavior identified by Greenberg (1990) that resulted from reduced employee pay rates, which were implemented by management without clear rationale.

\section{Negative Sentiments and Productivity}

Acting fair and equitably is generally expected, which is one reason why positive sentiments of employees may not be as noticeable in an organization as negative ones. Negative sentiments resulting from inequities will spread rapidly throughout an organization, requiring a significant amount of time on the part of the sport manager to try and diminish. The negative sentiments that are felt and disseminated across the organization can be damaging to productivity and also to the professional standing of the sport manager.

Unbalanced inputs and outputs create negative sentiments between the employee and sport manager who are the direct participants in the input-output exchange. Negative behaviors can extend beyond the employee and sport manager. Interestingly, such negative behaviors resulting from an unbalanced equity relationship between employee and sport manager often ends up taking place between two or more employees and involves the sport manager to a lesser extent.

Negative sentiments from unbalanced input-output exchanges will seep through the employee workforce in the organization. When colleagues learn that an employee is gaining outputs that are not in proportion with other employees' outputs who are contributing an equal degree of inputs, sentiments destructive to organizational productivity become present across the employee workforce. One might initially assume that employees would be unaffected by a co-worker who, when compared to other co-workers, was receiving fewer outputs than them. However, inequities regardless of who is favored or disfavored, ultimately run the risk of creating a work environment filled with negative sentiments that eventually move in a direction of negative behaviors destructive to the sport organization's productivity.

\section{Negative Employee Behaviors}

Inequities against employees generate dissatisfaction and frustration (Maslow, 1963). Maslow explained that when an inequity favors a person, that person experiences guilty feelings and when an inequity is against a person, that person often becomes dissatisfied and frustrated. When an employee experiences an inequity to the point of frustration, the employee may choose to voice and spread his frustration to anyone who will listen, which can contaminate the workplace. Here again, it is evident that it is in the best interest of the sport manager to meet employee inputs with the appropriate outputs to ensure the perception of equity on the part of the employee.

Employees are usually aware of the input-output exchange between their co-workers and the sport manager and constantly conduct their own informal equity analysis. Employees who feel they are victims of inequities will take it upon themselves to attempt to balance outputs with inputs so that they gain a sense of fairness.

Minor inequities can often be remediated with discussions ending in agreements that call for minor modifications of inputs to outputs or vice-versa. If, however, perceptions of inequities in a sport organization became the norm, employees will continue on a larger scale to engage in efforts to take it upon themselves to balance the input-output exchange. Some employees will meet with their supervisors in an attempt to negotiate a better deal (Bell, 2011). In other cases, when employees feel the distress of inequities, according to Bell, they quit their job. 
Turnover, generally, is higher across employees who are faced with inequities than those who are not (Hochwarter, Amason, \& Harrison, 1995).

Instead of aggressively attempting to balance the input-output exchange, in the event of unfairness, employees may simply choose to part ways with the organization in pursuit of another organization that offers a satisfactory input-output balance. When employees disrupt and/or dismiss organizational protocol for the purpose of "righting" perceived wrongs against them, the organization moves toward dysfunction. A well-functioning, productive sport organization is supported when employee inputs are met equitably with sport manager outputs.

\section{Transparency and Communication}

Transparent communication by organizational leaders, according to Jiang and Men (2017) is a precursor to employee engagement, which supports productivity. From a preventative standpoint, a good manager will use communication to directly confront distortions of facts to rebalance employees' attempts to reduce inequity for themselves (Bell, 2011).

Sport managers must be able to justify the outputs being provided to employees for their inputs to the sport organization. At the outset, transparent communication on the part of the sport manager will help clarify the perceptions of input and outputs to those in the sport organization. Throughout the input-output exchange, communication should be used to directly confront distortions of facts that might cause employees to seek to take it upon themselves to reduce inequities for themselves (Bell, 2011).

Usually job expectations vary from employee-to-employee, making the task of balancing the equity relationship across different employees challenging. Justification of outputs on the part of the sport manager will be received more favorably if a clear and transparent organizational mission is established, preferably with employee input and, hopefully employee buy-in. Employees who are involved in mission development and who remain informed of its goals and objectives are generally motived to perform for the sport organization.

The sport manager's arbitrary and inconsistent allocation of outputs without a transparent process or in disregard for the process in place is not conducive to a fully productive work environment. Transparent communication is essential and will help mitigate negative sentiments on the employees' part due to lack of information or misinformation (Greenberg, 1990). Efforts to achieve equity must be assumed by the sport manager, who must not only initiate the effort but also educate the workforce as to the purpose of the process and how it will take place.

\section{Conclusion}

Balancing the employee input and sport manager output exchange to achieve equity across employees, supports a functional sport organization conducive to maximizing employee productivity, which support the goals of the organization. This input-output exchange is a process that can take place with less resistance if efforts are focused on screening and hiring employees whose interests are congruent with the sport organization's mission. The often dynamic nature of sport organizations calls for constant maintenance of input-output exchanges on the part of both the employee and sport manager if equity balance is to be maintained. A full understanding of and shared interest between employee and sport manager in achieving the goals and objectives of the mission of the organization is necessary if an equitable input-output balance is to be achieved. Transparent communication of the input- 
output exchange process is necessary if the sport manager is to manage the process equitably, which supports a work culture of employee satisfaction and productivity. When the perceptions of the input-output exchange is perceived as equitable by both the employee and sport manager, the climate of the sport organization is one that supports productivity.

\section{REFERENCES}

Adams, J.S. (1963). Toward an understanding of inequity. Journal of Abnormal and Social Psychology, 67, 422436.

Alonzo, V. (2007). Maritz launches suite of tools to max employee recognition. Meeting News, 31(8), 18.

Aslam, W., \& Mundayat, A. A. (2016). Impact of fringe benefits on organizational performance mediating role of Employees satisfaction. Proceedings of the Multidisciplinary Academic Conference, 161-184.

Bell, R. L. (2011). Addressing employees' feelings of inequity: capitalizing on equity theory in modern management. Supervision, 72(5), 3.

Burtaverde, V., \& Mihaila, T. (2013). Personnel fluctuation in a human resources consultancy agency. Romanian Journal of Experimental Applied Psychology, 4(2), 97-109.

Childs, D. (2009). Improving employee productivity and efficiency. Government Finance Review, 25(2), 52-55.

Cowherd, D. M., \& Levine, D. I. (1992). Product quality and pay equity between lower-level employees and top management: an investigation of distributive justice theory. Administrative Science Quarterly, 3(7), 302-320. doi:10.2307/2393226

Greenberg, J. (1990). Employee theft as a reaction to underpayment inequity: The hidden cost of pay cuts. Journal of Applied Psychology, 75(5), 561-568. doi:10.1037/0021-9010.75.5.561

Hay, E. N. (1948). Salary management brings about equity and employee satisfaction. Bankers Monthly, 655.

Hochwarter, W. A., Amason, A. C., \& Harrison, A. W. (1995). Negative affectivity as a moderator of the inequity-turnover relationship. Journal of Social Behavior \& Personality, 10(4), 757-770.

Jiang, H., \& Men, R. L. (2017). Creating an engaged workforce. Communication Research, 44(2), $225-243$. doi:10.1177/0093650215613137

Khalifa, M.H.E., \& Truong, G. (2010). The relationship between employee perceptions of equity and job satisfaction in the Egyptian private universities. Eurasian Journal of Business and Economics, 3(5), $135-150$

Spell, C. S., \& Bezrukova, K. (2012). Perceptions of justice in employee benefits. In N. P. Reilly, M. J. Sirgy, C. A. Gorman, N. P. Reilly, M. J. Sirgy, C. A. Gorman (Eds.), Work and quality of life: Ethical practices in organizations (pp. 237-249). New York, NY, US: Springer Science + Business Media. doi:10.1007/978-94-007-4059-4_13. 